\title{
Identifying Effectiveness of Supply Chain Management Using Fuzzy Customer Feedback System
}

\author{
Sayed Sayeed Ahmad ${ }^{1}$, Harsh Purohit ${ }^{2}$ and Manuj Darbari ${ }^{3}$ \\ ${ }^{1}$ College of Engineering and Computing, Al Ghurair University, Dubai, UAE, E- \\ mail:sahmed@agu.ac.ae \\ ${ }^{2}$ Faculty of Management Studies, WISDOM, Banasthali Vidyapith, Rajasthan, E- \\ mail: \\ ${ }^{3}$ Computer Science \& Engineering Department, BBD University, Lucknow, E- \\ mail:
}

\begin{abstract}
The product quality is an important aspect that directly affects the supply chain management. The production of low quality products in the market leads to failure in their operational mode. This hurts the trust of customers on the company and creates a bad image of company in the market. The continuous degrade in the quality may lead to a big financial loss in the company. In this paper an approach related to the generation of a index to a particular company that can be used further in the supply chain management strategy change. The proposed system is implemented using Fuzzy System using FISPro, open access software tool.
\end{abstract}

Keywords: Fuzzy Sets, Guaje, Supply Chain Management, Product Quality

\section{Introduction}

Supply chain management [1-2] is the systematic approach to deal with the issues from raw material to the delivery of the product in the market. A supply chain is a network of facilities and distribution options that performs the functions of procurement of materials, transformation of these materials into intermediate and finished products, and the distribution of these finished products to customers [3-4]. Supply chains exist both in service and manufacturing organizations. An essential condition to the success of a company is the conception of a strategy for coordinating the several business unities in a supply chain, leading to an effective management at strategic, tactical and operational levels. The efficiency of a supply chain is influenced by several factors, such as: stock management, production planning, production costs, scheduling and distribution strategies, and customer-specific demand, among others [5]. Planning and modelling the production, stocking and distribution systems of a supply chain is an important support for decision making in a competitive market.

Humans are capable to use linguistic information precisely in their decision making. Due to imprecise and uncertain nature of the linguistic information, machines are not capable to use them in decision making processes using traditional methods. To make the machines intelligent, like humans in this regard, Fuzzy Techniques are used.

The idea of the Fuzzy Logic [12] was first introduced by Professor Lotfi Ahmad Zadeh, at University of Berkeley, California in his seminal paper "Fuzzy Sets".

Fuzzy Logic is a form of multi-valued logic derived from fuzzy set theory to deal with approximate reasoning. It provides the means to represent and process the linguistic information and subjective attributes of the real world. Fuzzy Logic is the extension of Boolean Crisp Logic to deal with the concept of partial truth. Fuzzy Logic is applied in the number of areas, i.e. engineering applications, medical applications, economics and 
management, industrial applications and many more. It is also integrated with other soft computing techniques, like Neural Network (an approach that mimics the functionality of human brain), Genetic Algorithms (a nature inspired search and optimization technique), PSO (Particle Swarm Optimization) etc.

In the early stage of the Fuzzy Logic, a number of misconceptions have been created. Here we are going to introduce few points about fuzzy logic to make the concept very clear.

1. Fuzzy logic is not fuzzy.

2. Fuzzy logic is precise.

3. Fuzzy Logic is a precise system of reasoning, deduction and computation in which the objects of discourse and analysis are associated with information, which is or is allowed to be imperfect.

4. Any formal system can be fuzzified.

Rule Base Systems are highly applicable in decision making, control systems and forecasting. To deal with imprecise, uncertain and inexact real world knowledge, in rule based systems, fuzzy techniques are used. Fuzzy logic is the way to represent the complex situations in terms of simple natural languages.

\section{Related Work}

Supply chain risk management is an important research issue. A guided framework related to this issue has been developed in [6]. The research agenda related to this issue has been developed in [7]. Sometimes the network of supply chain management is very complex and not easy to handle. The issue of complexity in supply chain network is explained in [8]. The critical issue of supply chain risk is well addressed in [9-11].

Fuzzy Systems and evolutionary multi-objective optimization are applied in many areas and have a big scope of improvement. An improvement in interpretability-accuracy trade-off is well addressed in [13, 17-19]. A new optimization based interval type-2 fuzzy knowledge base system has been developed with an improvement strategy of LDEC approach in [14]. The problem of high dimensionality is addressed in [15]. Also the interpretability-accuracy trade-off issue is handled in the multi-objective fuzzy systems in [16].

\section{Proposed Model}

The proposed model classifies the companies into three classes using four customer parameters.

The product quality comprises of different issues like durability, effects of physical hazards, operating mishandling effects etc. Market availability shows the ease of purchasing the particular product in the market. It is related to the availability of product in the market. Maintenance service is related to the ease of customer during the physical servicing of product or disqualified product before warrantee. The company service centers are directly involved with this issue. Cost compare factor analyze the cost of similar products in the market.

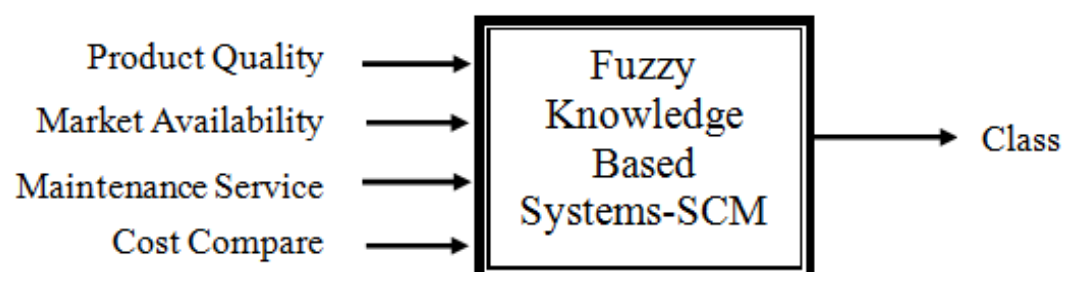

Figure 1. Fuzzy Knowledge Based Systems 


\section{Implementation}

The proposed system is implemented using FISPRO open access software. The membership functions of input and output variables are given below.
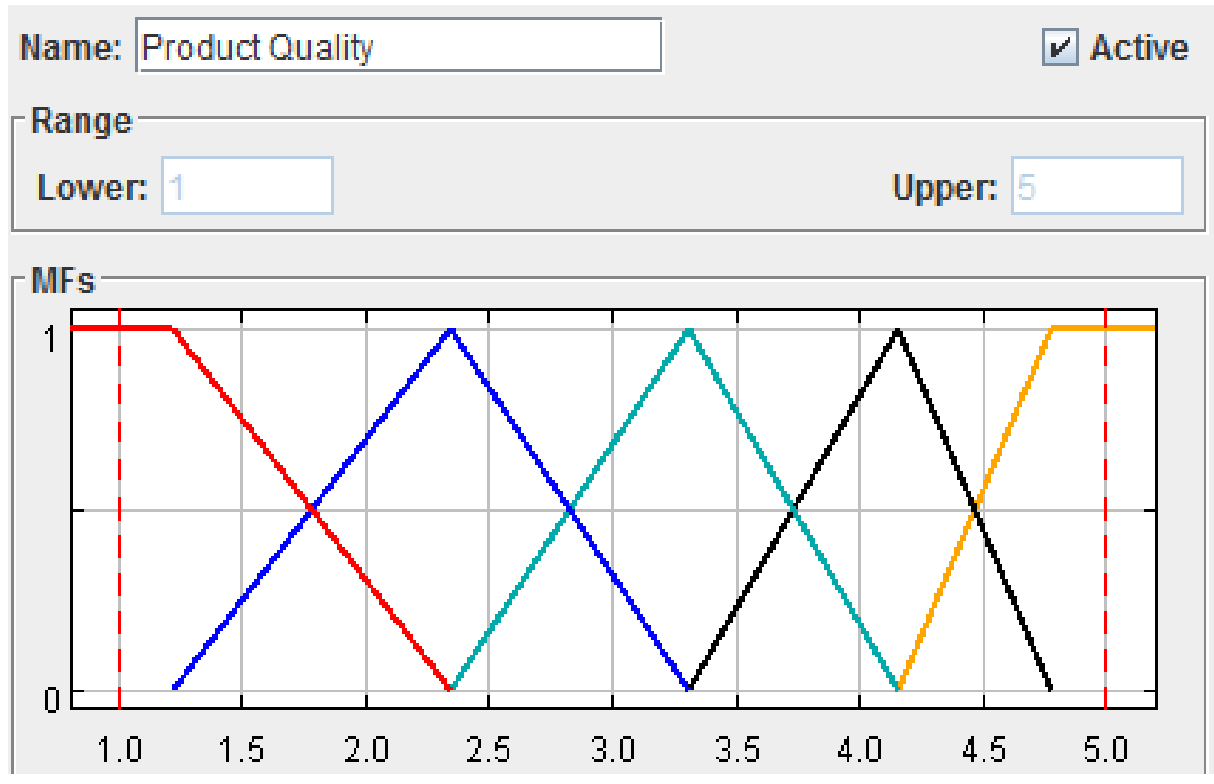

Figure 2. Membership Function 1

\begin{tabular}{ll} 
Name: Market Availability & $\nabla$ Active \\
-Range & \\
Lower: 1 & Upper: 5 \\
\hline
\end{tabular}

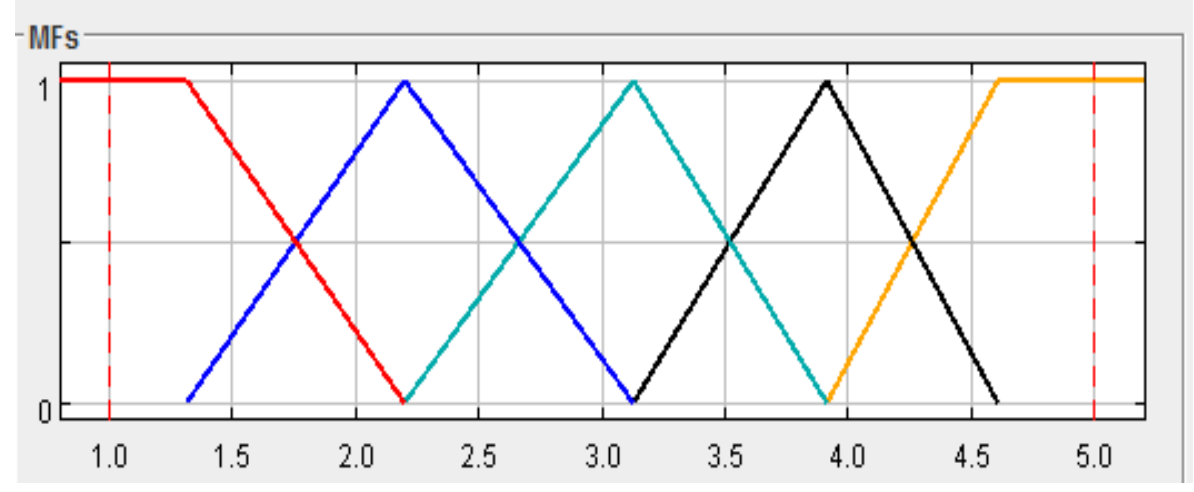

Figure 3. Membership Function 2 


Name: 1 Maintance Service
\begin{tabular}{ll} 
Range \\
Lower: 1 & Upper: 5 \\
\hline
\end{tabular}

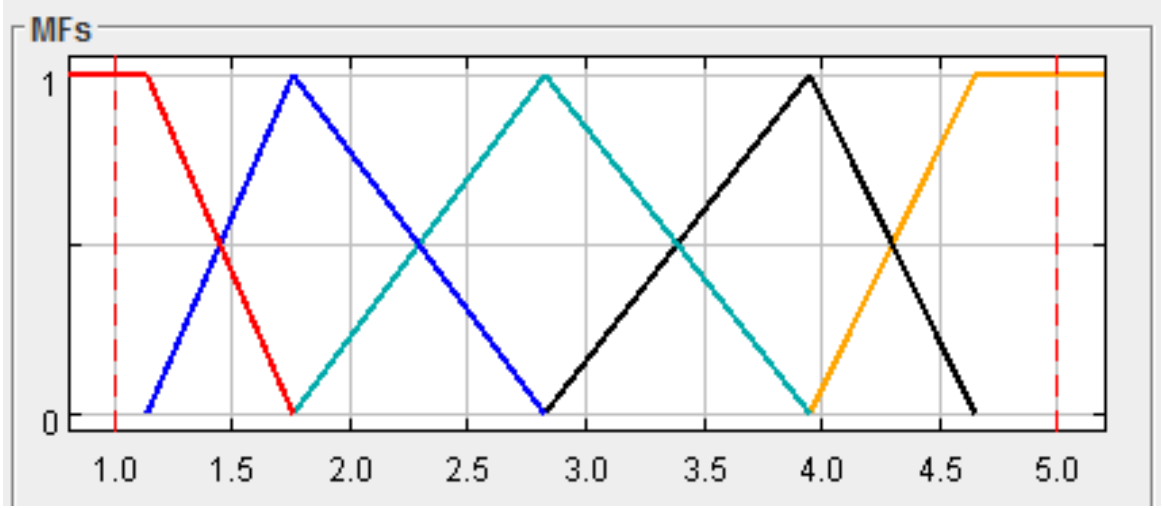

Figure 4. Membership Function 3
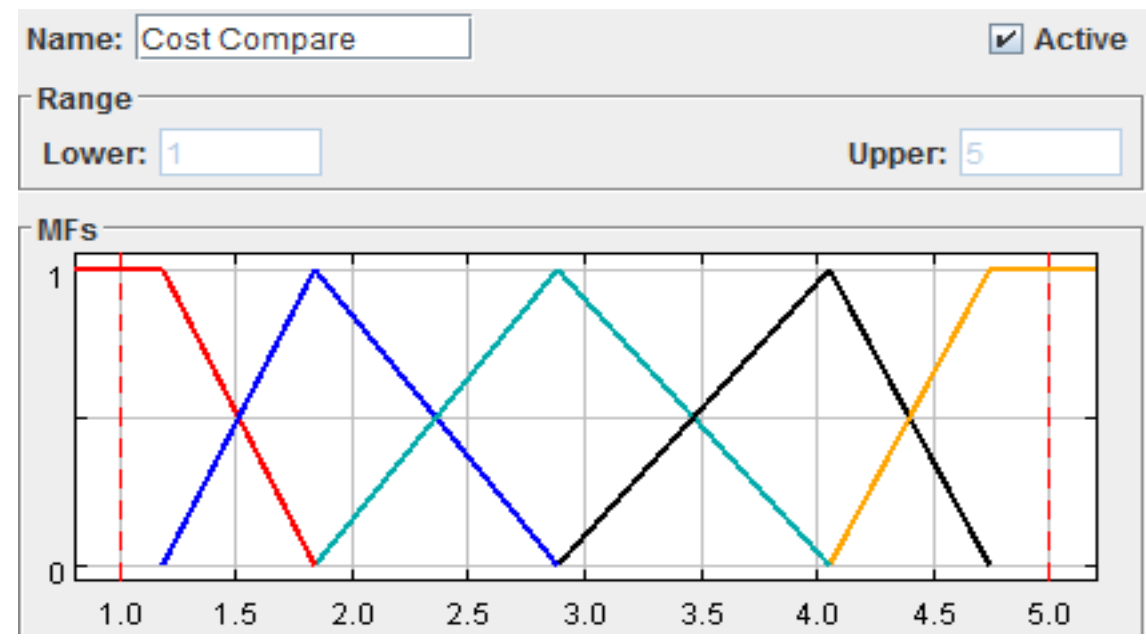

Figure 5. Membership Function 4

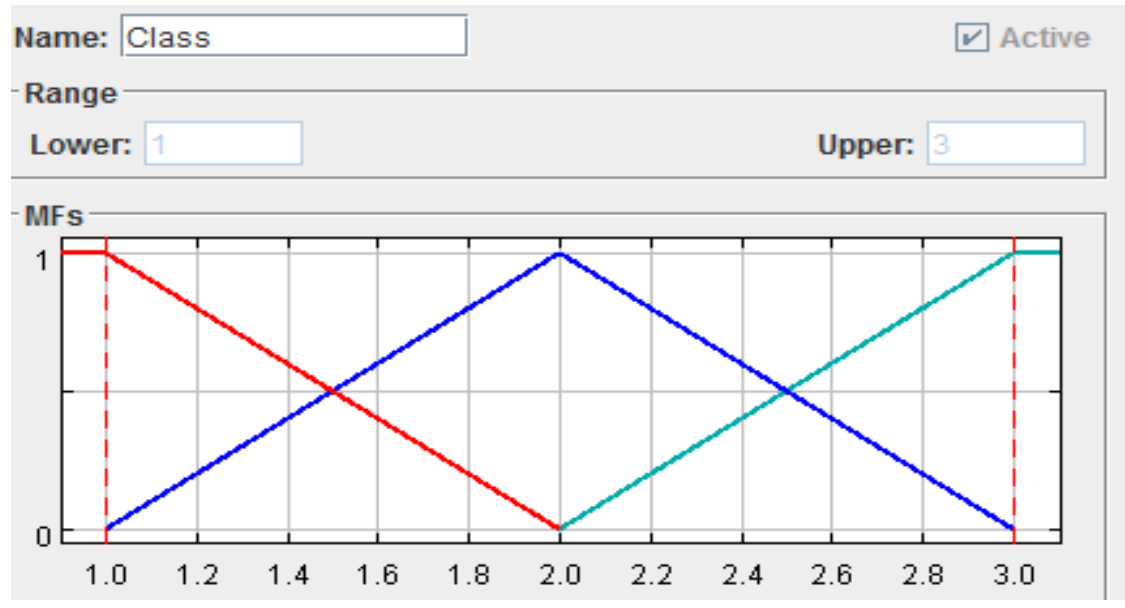

Figure 6. Membership Function 5 


\section{Experiment-1}

Wang Mendel procedure has been used to generate the rules. The other settings are as follows;

Parameter for inference: Conjunction

Defuzzfication: area

Membership Function: Semi trapezoidal

\section{Experiment-2}

Fuzzy Decision Tree method is used for rule generation for the inference. The parameters are as follows;

Maximum tree depth $=4$

Minimum significant level $=0.2$

Leaf minimum cardinality $=4$

Tolerance threshold $=0.1$

Minimum entropy $=0.001$

Coverage threshold $=0.9$

\section{Experiment-3}

This is an optimization experiment using Soil Wetts method. All the input parameters are optimized in this experiment.

The parameters are as follows;

Loss of coverage $=10 \%$

Blank threshold $=0.1$

Number of loops $=10$

Soil Wets Constants

$\mathrm{I} 1=0.4 \quad \mathrm{I} 2=0.2 \quad \mathrm{I} 3=0.5$

Standard Gaussian Noise $=0.005$

Maximum number of constraints $=1000$

Maximum number of iterations $=100$

The cross-validation approach is used to carry out optimization.

Table 1. Experimental Results

\begin{tabular}{|c|c|c|c|}
\hline Results & Experiment-1 & Exeriment-2 & Experiment-3 \\
\hline PI & 0.06 & 0.018 & 0.025 \\
\hline RMSE & 0.383 & 0.121 & 0.163 \\
\hline MAE & 0.175 & 0.052 & 0.076 \\
\hline Coverage & $95 \%$ & $100 \%$ & 100 \\
\hline Maximum Error & $1.815 \%$ & $0.456 \%$ & 0.678 \\
\hline
\end{tabular}




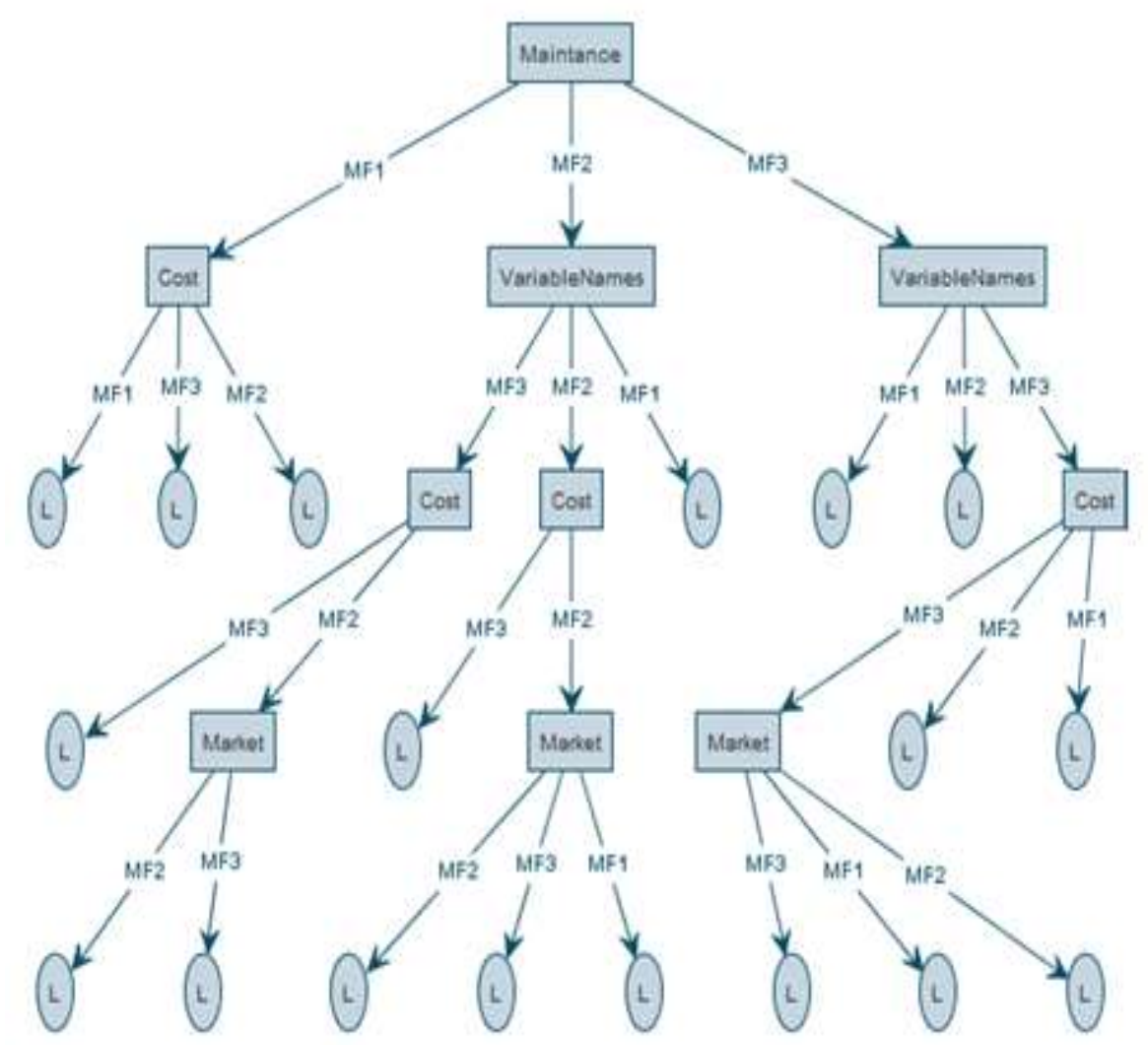

Figure 7. Fuzzy Decision Tree-1 


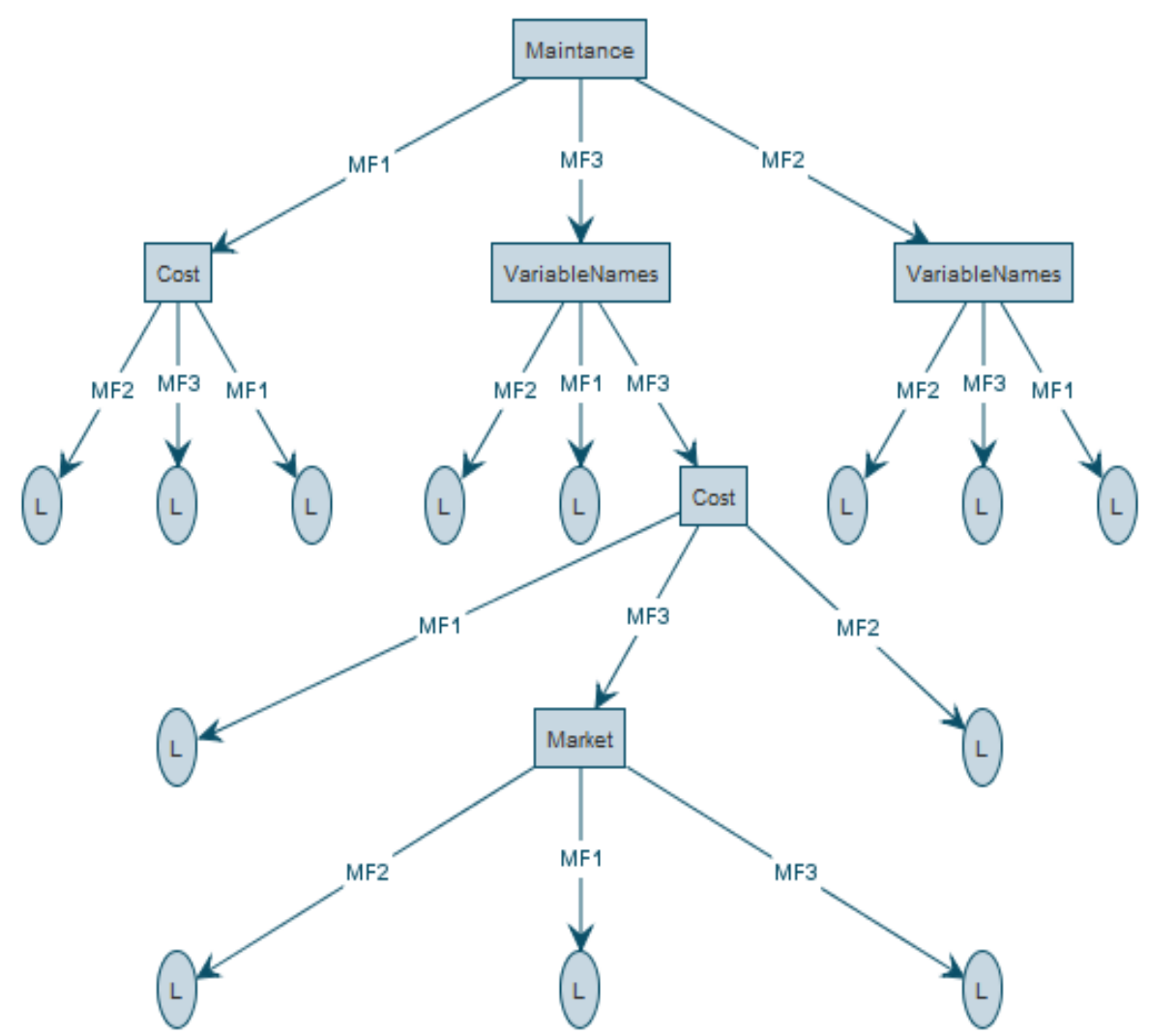

Figure 8. Fuzzy Decision Tree-2

\section{Conclusion and Future Scope}

Fuzzy systems are the approximate decision systems and are capable to make decisions in the environment of partial truth and uncertainties. In the supply chain management, few parameters are imprecise and uncertain, especially the information collected from the customers as a feedback to know its effectiveness. This paper concludes the development of a customer feedback system using FISPRO open access software. The results are found satisfactory and competitive with the contemporary approaches.

\section{References}

[1] M. N. Faisal, D. K. Banwet and R. Shankar, "Supply chain risk mitigation: modelling the enablers", Business Process Management Journal, vol. 12, no. 4, (2006), pp. 535-52.

[2] F. Cucchiella and M. Gastaldi, "Risk management in supply chain: a real option approach", Journal of Manufacturing Technology Management, vol. 17, no. 6, (2006), pp. 700-720.

[3] C. S. Tang, "Perspectives in supply chain risk management", International Journal of Production Economics, vol. 103, no. 2, (2006), pp. 451-488.

[4] T. Wu, J. Blackhurst and V. Chidambaram, "A model for inbound supply risk analysis", Computers in Industry, vol. 57, no. 4, (2006), pp. 350-65.

[5] J. G. M. Lim and F. Meng, "A stochastic model for risk management in global supply chain networks", European Journal of Operational Research, vol. 182, no. 1, (2007), pp. 164-173.

[6] B. Ritchie and C. Brindley, "Supply chain risk management and performance: a guiding framework for future development", International Journal of Operations and Production Management, vol. 27, no. 3, (2007), pp. 303-322.

[7] O. Khan and B. Burnes, "Risk and supply chain management: creating a research agenda", International Journal of Logistics Management, vol. 18, no. 2, (2007), pp. 197-216.

[8] X. Li and C. Chandra, "A knowledge integration framework for complex network management", Industrial Management \& Data Systems, vol. 107, no. 8, (2007), pp. 1089-1109. 
[9] U. Jüttner, "Supply chain risk management", International Journal of Logistics Management, vol. 16, no. 1, (2005), pp. 120-141.

[10] D. Wu and D. Olson, "Supply chain risk, simulation, and vendor selection", International Journal of Production Economics, vol. 114, no. 2, (2008), pp. 646-655.

[11] S. Rao and T. J. Goldsby, "Supply chain risks: a review and typology", the international Journal of Physical Distribution \& Logistics Management, vol. 20, no. 1, (2009), pp. 97-123.

[12] J. K. Klir, and B. Yuan, "Fuzzy Sets and Fuzzy Logic", Prentice Hall India, (1995).

[13] P. K. Shukla and S. P. Tripathi, "A review on the interpretability-accuracy trade-off in evolutionary multi-objective fuzzy systems (EMOFS)”, Information, vol. 3, no. 3, (2012), pp. 256-277.

[14] P. K. Shukla and S. P. Tripathi, "A new approach for tuning interval type-2 fuzzy knowledge bases using genetic algorithms", Journal of Uncertainty Analysis and Applications, vol. 2, (2014), pp. 1-15

[15] P. K. Shukla and S. P. Tripathi, "Handling high dimensionality and interpretability-accuracy trade-off issues in evolutionary multi-objective fuzzy classifiers", International Journal of Scientific \& Engineering Research, vol. 5, no. 6, (2014), pp. 1-6.

[16] P. K. Shukla and S. P. Tripathi, "Interpretability and accuracy issues in evolutionary multi-objective fuzzy classifiers", International Journal of Soft Computing and Networking, vol. 1, no. 1, (2016), pp. 5568.

[17] P. K. Shukla and S. P. Tripathi, "A Survey on Interpretability-Accuracy Trade-Off in Evolutionary Fuzzy Systems", IEEE International Conference on Genetic and Evolutionary Computation (ICGEC), Japan, (2011).

[18] P. K. Shukla and S. P. Tripathi, "On the Design of Interpretable Evolutionary Fuzzy Systems (I-EFS) with Improved Accuracy”, International Conference on Computing Sciences, LP University, India, (2012).

[19] P. K. Shukla and S. P. Tripathi, "Interpretability Issues in Evolutionary Multi Objective Fuzzy Knowledge Base Systems", 7th International Conference on Bio-Inspired Computing: Theories and Applications (BIC-TA 2012), ABVIIITM, Gwalior, India, (2012). 